\title{
Analysis of Results of SARS-CoV-2 RT-PCR Testing and Pooling Strategies for Screening of Asymptomatic Individuals - The Philippine Children's Medical Center Experience
}

Danielle Anne Gonong, Grig Misiona, Melani Sionzon, Farrah Kristine Santiago, Aquiles Joseph Lira, Raymundo Lo

Philippine Children's Medical Center

\section{ABSTRACT}

Background. The availability of reverse transcription-polymerase chain reaction (RT-PCR) in detecting severe acute respiratory syndrome coronavirus 2 (SARS-COV-2) is limited by the scarcity of resources prompting the use of pooling strategies. Evaluated in this study is the Philippine Children's Medical Center's (PCMC) experience in pooled testing done in asymptomatic population.

Objectives. Review the pooled SARS-CoV-2 RT-PCR results and case investigation forms (CIF) in asymptomatic population. Determine the incidence of SARS-COV-2 in asymptomatic population and compare all the individual and pooled tests results. Determine the number of saved test kits and identify clustering in the community.

Methodology. This is a retrospective study that reviewed the pooled and individual SARS-COV-2 RT-PCR results using Allsheng Auto-Pure 32a extraction kit, Sansure Biotech PCR machine and Maccura Sars-CoV-2 test kits. The pooling protocol used by the institution followed the recommendation by Lo et al., in the study entitled "An Evaluation of Pooling Strategies for RT-qPCR testing for SARS-CoV-2 infection."

Results. There are 1828 samples which resulted to 165 negative, 68 indeterminate, and 137 positive pools. There are 157, 135, and 68 pools containing 5 individual samples that were classified as negative, positive and indeterminate pools, respectively. Additionally, the negative pools contained 8 pools with 3 individual samples and the positive pools contained 2 pools with 2 individual samples. Deconvolution of the positive and indeterminate pools resulted to 227 and 74 positive individuals, respectively. In this review, the laboratory saved $24 \%$ of the test kits and shorten the overall turnaround time by 23 hours.

Conclusions and Recommendations. The incidence of SARS-COV-2 in the population is higher compared to the prevalence of infection in the country. Pooled testing conserved test kits and congruence of pooled and individual ORF Ct-values was observed. An in-depth study including other genes is recommended and assessment of pooling in other population may be pursued.

Key words: reverse transcription-polymerase chain reaction, severe acute respiratory syndrome coronavirus 2, 2019 coronavirus disease

ISSN 2507-8364 (Online)

Printed in the Philippines.

Copyright $(02021$ by the PJP.

Received: 24 March 2021

Accepted: 20 May 2021.

Published online first: 30 June 2021

https://doi.org/10.21141/PJP.2021.03

Corresponding author: Danielle Anne G. Gonong, MD

E-mail: danielle.anne.gonong@gmail.com

\section{INTRODUCTION}

\section{Statement of the Problem}

Coronavirus disease of 2019 (COVID-19) is caused by SARS-CoV-2, and was declared a pandemic in March 2020 by the World Health Organization (WHO). ${ }^{1}$ The gold standard for the detection of SARS-CoV-2 is by nucleic acid amplification testing (NAAT) with the use of RT-PCR. In the Philippines, mass testing is limited by the expense of SARS-CoV-2 tests and the number of accredited testing laboratories. These test limitations compelled the Department of Health (DOH) to make guidelines on testing for COVID-19 that are geared towards symptomatic and high-risk individuals, those with travel history, and health care providers. ${ }^{2}$ However, despite these guidelines, the need for mass testing is apparent to survey the population.

On August 17, 2020, the Philippine Society of Pathologists Inc. (PSP) announced that pooled testing can be used as a strategy to minimize the number of test kits utilized 
and decongest the backlog in accredited testing centers. The society further recommends that pools of five are the most cost-effective strategy to use given the prevalence of infection in the country. ${ }^{3}$ On November 23, 2020, The DOH released a guideline on the conduct of COVID-19 pooled testing. ${ }^{4}$

Pooled testing is a strategy wherein samples are grouped into a particular number of pools. If the pooled sample result is negative, all the samples in that pool are presumed negative. Otherwise, if pooled sample is positive or indeterminate, all the specimens in the pools are tested individually. ${ }^{5}$

Majority of the literature available regarding pooled testing are done theoretically or in a small scale. In this study, the application of pooling in a community setting involving asymptomatic individuals was evaluated.

\section{Significance of the Study}

Due to the emerging numbers of SARS-CoV-2 positive asymptomatic individuals, mass testing became essential in the battle against COVID-19. As a strategy to facilitate mass testing, the PSP recommended pooling strategies to make tests available to the general population. Reviewed in this study were samples submitted for SARS-CoV-2 RTPCR pooled testing from asymptomatic population in a local government unit (LGU). More so, the study aims to review the turnaround time and cost-effectivity of pooled testing in the asymptomatic population.

\section{Review of Literature}

The first case of COVID-19 was reported in Wuhan City, China in December 2019. Clinical symptoms of COVID-19 in patients vary but they often present with acute respiratory illness. In early January 2019, SARS-CoV-2 was identified as the causative agent of COVID-19. ${ }^{6}$ SARS$\mathrm{CoV}-2$ is a $\beta$-coronavirus characterized by an enveloped non-segmented positive-sense RNA virus from subgenus sarbecovirus and subfamily Orthocoronavirinae. ${ }^{7}$ The most common mode of transmission by SARS-CoV-2 is thru droplet expelled during talking, sneezing or coughing, however other modes like contact surface spread and aerosol transmission were reported. It is evident that a high risk of transmission is associated with prolonged exposure to an infected person, especially if these individuals are symptomatic, while exposure to asymptomatic contacts are less likely to result in transmission. ${ }^{8}$ Despite limited literatures on asymptomatic infections of COVID-19 cases, a systemic review by Gao et.al showed that there are significant proportion of SARS-CoV-2 RT-PCR positive asymptomatic cases at $1.6 \%$ in China, 30.8\% in Japan, $51.7 \%$ in Diamond Princess, $10.7 \%$ in Korea, $56.5 \%$ in Washington and $15.8 \%$ in Wuhan Children. ${ }^{9}$

The detection of SARS-CoV-2 was made possible by identifying the complete genomic structure of WuhanHu-1 coronavirus (WHCV), a strain of SARS-CoV-2 isolated from a COVID-19 worker in the Wuhan seafood market. It was shown that the genome of WHCV contains variable number of ORF. Majority of the viral RNA are in the first ORF that translates two polyproteins, ppla and pplab and encodes 16 non-structural proteins (NSP), while the remaining ORFs encode accessory and structural proteins. The other essential structural proteins encoded by the virus are spike (S) glycoprotein, small envelope (E) protein, matrix (M) protein, and nucleocapsid (N) protein. There are several emerging tests for SARS-CoV-2, but the current gold standard is by NAAT which includes RT-PCR. RT-PCR is a laboratory test that converts short strands of ribonucleic acid (RNA) to deoxyribonucleic acid (DNA). The newly formed DNA strands undergo amplification until a measurable amount is detected known as the Ctvalue. ${ }^{6}$ In a review of eighteen literatures done by Rao et.al., it was concluded that the Ct-value is significantly associated with the viral load. The review further concluded that lower Ct-value is associated with a meager clinical outcome and may be useful in predicting the clinical course and prognosis of the patient. ${ }^{10}$

Due to the rapid spread of the virus and increase in the demand for tests, limited numbers of test kits and overflowing backlogs of testing laboratories have become a major hindrance in the fight against this pandemic. Several testing strategies are being studied to address the challenges of testing, and one of the options proposed is pooled testing. Pooled testing is a testing scheme that is directed towards minimizing the number of tests conducted using pooled subsets. If a pool of $\mathrm{n}$ sample tests are negative, all the samples are considered negative while positive and indeterminate pools will be tested in individually. ${ }^{11}$

As of April 23, 2021, there are 144,358,956 confirmed cases of COVID-19 with 3,066,113 mortality as per the World Health Organization. ${ }^{12}$ In the Philippines there are 971,049 COVID-19 confirmed cases and 16,370 of whom died. ${ }^{13}$ Despite the guidelines set to conserve testing, it is now evident that large-scale population testing which can be achieved by pooling is necessary to survey asymptomatic population, to trace asymptomatic COVID-19 carriers that are difficult to identify and isolate, to assure that healthcare workers are not contagious, to screen and protect high risk population, to accurately estimate the spread of infection, to assess the effectiveness of quarantine measures and social distancing, and to allow the safe return to work. ${ }^{14}$

\section{Summary of Literature on Pooled Testing in Asymptomatic Population}

Das et al., conducted a surveillance study on SARS-CoV-2 RT-PCR using pooled testing involving 7,000 asymptomatic individuals. These samples were grouped into 700 pools and only eight pools were positive. All positive pools yielded only one positive specimen each after subpooling. An incidence of $0.11 \%$ positivity was taken from the pooled asymptomatic cases and the experiment was able to save 6,220 test kits. $^{15}$

A pooling study conducted by Lohse et.al involves 1191 samples from asymptomatic population. In this study the prevalence of SARS-CoV-2 using RT-PCR pooling strategy is $1.93 \%$ and the researchers were able to save 924 test kits. ${ }^{16}$

In a pooled testing study done in Kenyan Coast, there are 1500 samples submitted, wherein 250 pools are taken (6 samples in each pool). There are 75 positive pools, and individual runs of the positive pools resulted in 112 positive samples (7.5\% from the original 1500 samples). It 
was further noted that positive pools with lower Ct-values contain multiple positive individuals. Moreover, pooled samples with multiple positive individuals had an average decrease of Ct-value by 1.59 in comparison to pooled samples with single positive individual. ${ }^{17}$

A pooled study involving hospitalized patients that have low risk for SARS-CoV-2 was done using Xpert Xpress SARS-CoV-2 test which involved 530 samples pooled in groups of 3 . This resulted in 4 positive pools and a total of 179 pooled samples with a positivity rate of $0.8 \% .^{18}$

\section{OBJECTIVE OF THE STUDY}

\section{General Objectives}

To analyze the pooled SARS-CoV-2 RT-PCR test results in conjunction with the data seen in the CIF of nasopharyngeal and oropharyngeal (NP/OP) samples submitted by a LGU at PCMC on September 2, 2020 to September 8, 2020.

\section{Specific Objectives}

- Determine the incidence of asymptomatic individuals with SARS-CoV-2 that are detected by RT-PCR using pooling strategies.

- Determine how pooled sample results affect individual testing.

- Determine if pooled testing can conserve test kits in a large-scale population.

- Determine if clustering of SARS-CoV-2 positive asymptomatic individuals can be detected by pooling strategies.

\section{Operational Definition of Terms and Variables}

RT-PCR - A laboratory technique that combines reverse transcription of RNA into DNA with amplification of specific DNA targets using polymerase chain reaction.

Pooled testing - Testing scheme done wherein individual samples are pooled into a certain number. If the pooled sample is negative, all individual samples are considered negative. Otherwise, if pooled sample is positive or indeterminate, subpooling or individual testing of specimens will be done.

Ct-value - Number of cycles required for fluorescent signal to cross the threshold for detection of gene amplification. This is inversely proportional to the amount of target nucleic acid in the sample.

\section{METHODOLOGY}

\section{Research Design}

This is a descriptive study that retrospectively reviewed the NP/OP specimens and CIF submitted at PCMC from a LGU on September 2, 2020 to September 8, 2020 for SARS-CoV-2 RT-PCR pooled testing. The pooling method and interpretation used was patterned after the prior study of Lo et al. ${ }^{3}$

\section{Subject and Sample Size Computation}

The minimum sample size of the study is 1429 , this was computed using Epi Info version 7.2.2.6. The sample size of the study was estimated using single population proportion formula with the following assumptions:
99\% confidence interval, $1.0 \%$ margin of error, and $2.2 \%$ frequency of PCR-confirmed asymptomatic SARS-CoV-2 cases in the Philippines. The population of the study was limited to asymptomatic individuals aged 19 years old and above. These samples were taken from different barangays, agencies and includes tricycle drivers and market vendors in a LGU.

\section{Description of the Study Procedure}

A review of the SARS-CoV-2 RT-PCR test results using Macurra's SARS-CoV-2 Fluorescent PCR kit was done. The Macurra's SARS-CoV-2 Fluorescent PCR kit is a qualitative assay that allows the detection of SARS-CoV-2 nucleic acids, namely, ORF, E, and $\mathrm{N}$ gene. The Macurra's SARSCoV-2 Fluorescent PCR kit is approved by the National Medical Products Administration, Certification Experts and the Food and Drug Administration of the Philippines.

The pooled samples were reviewed to assure that the following classifications were followed: negative, positive, and indeterminate pools ( $\mathrm{N}$ gene only, $\mathrm{N}$ and/or $\mathrm{E}$ genes and late amplification of the ORF gene). Descriptive analysis of the individuals called as negative and positive under the pooling classification were done.

\section{Testing Procedure}

The pooling strategy used was patterned after the study of Lo et al. In the study, pools of 5 was the recommended method and has a sensitivity of $83 \%$ and an estimated specificity of $100 \%$. From the submitted NP/ OP samples, an aliquot of $50 \mathrm{uL}$ were taken and pooled into groups of 5 which amounted to $250 \mathrm{uL}$ (pools that had 2 and 3 individual samples amounted to 100 to 150 $\mathrm{uL}$, respectively). The pooled samples were placed in a cryogenic vial and then mixed using a vortex mixer. After mixing, $50 \mathrm{uL}$ aliquots from the pooled samples were taken and underwent SARS-CoV-2 RT-PCR testing. All the specimens in the negative pools were considered negative. All the specimens in the pools that were classified as positive and indeterminate were tested individually.

The individual and pooled samples were tested using Macurra SARS-CoV-2 Fluorescent PCR kit, Allsheng Auto-Pure 32A extraction kit, and Sansure Biotech Ma600 RT-PCR machine. All procedures were performed in strict compliance with the biosafety guidelines and using the manufacturers' instructions. The results were then recorded and encoded in Microsoft Excel files.

\section{Results Interpretation}

Interpretation of individual results was patterned after Maccura SARS-CoV-2 Fluorescent PCR Kit. As quality control, every run must have a valid control (ORF Ct-value $</ 32$, internal control (IC) Ct-value $</ 38$, E Ct-value $</ 32$ and $\mathrm{N}$ Ct-value $</ 32$ ), otherwise samples are invalid and should be retested. Target genes are positive if the ORF, E, and $\mathrm{N}$ genes Ct-values are $</ 38,</ 37,</ 38$, respectively with a valid IC. Target genes are negative if there are no Ct-values or the ORF, E, N genes, and IC CT-values are $>38,>37,>38$, and $</ 38$, respectively. Based on these Ctvalues, samples are interpreted as follow: 1 . A positive ORF gene with presence of any positive $\mathrm{N}$ and/or $\mathrm{E}$ genes is positive, 2. A positive ORF gene with no $\mathrm{N}$ and/or $\mathrm{E}$ genes must be repeated, if still positive, this will be interpreted 
as SARS-CoV-2 positive, 3. Positive $\mathrm{N}$ and/or $\mathrm{E}$ genes with no ORF gene will be correlated with other medical findings, and if results are inconsistent with the clinical presentation, additional testing is suggested to confirm the results, otherwise result will be released as negative.

The interpretation of pools was patterned after Lo et al., and the Centers for Disease Control and Prevention (CDC). ${ }^{3,5}$ Pools that show no gene amplification with valid controls are interpreted as negative. Pools that showed a positive ORF gene with or without $\mathrm{N}$ and $\mathrm{E}$ genes are interpreted as positive. Pools that show any gene amplification other than ORF, any unusual or non-sigmoid amplification, and late or low amplification are interpreted as indeterminate.

\section{Data Collection and Outcomes}

All the data and CIF submitted from the LGU to PCMC last September 2, 2020 to September 8, 2020 for RT-PCR and pooling study were evaluated. The corresponding data that fit the inclusion criteria were reviewed to determine if sample pools were classified appropriately.

The results of pooled and individual tests in conjunction with the data in the CIF were tabulated and described statistically to determine the incidence, viral load, practicality, and cost-effectiveness of pooled testing in the community.

\section{Ethical Consideration}

An approval from the Institutional Review Board at PCMC was done prior to the commencement of the study. Confidentiality of the individuals included in this study was the highest priority. This research complied with the Data Privacy Act (2012) and National Ethical Guidelines for Health and Health-Related Research. The study's research assistant, gathered the raw data from the CIF and assigned the corresponding numerical value to all the samples to ensure patient's privacy. The research assistant tabulated the numerical values (age, gender, and demographic location) and removed any personal information and accession numbers. All the data taken from the study were stored in a flash drive and shall be kept for 5 years. Materials and data that were obtained from the study will be a property of PCMC and the researchers and not by the LGU. Should the LGU require any information from the study, they must do so in formal writing.

\section{Data Processing and Analysis}

The pertinent data were collated and statistically evaluated using Microsoft Excel. The demographic profile of included subjects were taken from the CIF and analyzed. The incidence of positive cases were calculated in asymptomatic individuals and were further evaluated as per pool and individual test results. The number of test kits used in the performed pooled testing strategy were compared to the number of projected test kits used should conventional RT-PCR had been done.

\section{RESULTS}

A total of $1828 \mathrm{NP} / \mathrm{OP}$ samples were evaluated from which there were 165 negative, 137 positive, and 68 indeterminate pools. The negative pools had 157 pools with 5 individual samples and 8 pools with 3 individual samples. The positive pools had 135 pools containing 5 individual samples and 2 pools containing 2 individual samples. All 68 indeterminate pools had 5 individual samples. All 809 samples within the negative pools were considered negative. The 137 positive pools contained 679 individual samples wherein $227(33 \%)$ were positive and the indeterminate pools contained 340 samples wherein $74(21.8 \%)$ individual samples were positive.

Table 1 shows the distribution of positive individuals in the deconvoluted pools. In the positive pools, there are 63 pools containing at least 1 positive sample, 52 pools containing 2 positive samples, 16 pools containing 3 positive samples and 3 pools containing 4 positive samples. The indeterminate pools were further subclassified into $\mathrm{N}$ gene, $\mathrm{N}$ and $\mathrm{E}$ genes, and late amplification. In pools with $\mathrm{N}$ gene amplification, there are 27 pools containing at least 1 positive sample, 9 pools containing 2 positive samples and 2 pools containing 3 positive samples. In pools with $\mathrm{N}$ and $\mathrm{E}$ genes amplification, there are 10 pools containing at least 1 positive sample and 3 pools containing 2 positive samples. In the pools with late amplification there are 7 pools with at least one positive sample.

Among the positive individual samples in the positive pools, $13(6 \%)$ had an ORF Ct-values of <20, $25(11 \%)$ had an ORF Ct-values between 20-25 and 189 (83\%) had an ORF Ct-values of $>25$. In the indeterminate pools, all the 68 positive individual samples had an ORF Ct values of $>25$. (Table 2 )

\begin{tabular}{|c|c|c|c|c|}
\hline \multirow{2}{*}{$\begin{array}{l}\text { Number of positive } \\
\text { samples per pool }\end{array}$} & \multirow{2}{*}{$\begin{array}{l}\text { Positive } \\
\text { Pools }\end{array}$} & \multicolumn{3}{|c|}{ Indeterminate Pools } \\
\hline & & $\mathbf{N}$ & $\mathrm{N}$ and $\mathrm{E}$ & Late amplification \\
\hline 1 & 63 & 27 & 10 & 7 \\
\hline 2 & 52 & 9 & 3 & 0 \\
\hline 3 & 16 & 2 & 0 & 0 \\
\hline 4 & 3 & 0 & 0 & 0 \\
\hline 5 & 0 & 0 & 0 & 0 \\
\hline
\end{tabular}

\begin{tabular}{|c|c|c|c|c|c|}
\hline $\begin{array}{l}\text { Pooled } \\
\text { Samples }\end{array}$ & $\begin{array}{c}\text { Individual } \\
\text { Samples } \\
\text { Interpretation }\end{array}$ & Number & $\begin{array}{c}\text { ORF } \\
\text { (Ct-values) }\end{array}$ & Number & $\begin{array}{l}\text { Ct-values } \\
\text { positive \% }\end{array}$ \\
\hline \multicolumn{6}{|l|}{ Negative: 165} \\
\hline \multicolumn{6}{|l|}{ Positive: 137} \\
\hline & \multirow{3}{*}{ Positive } & \multirow{3}{*}{227} & $<20$ & 13 & $6 \%$ \\
\hline & & & $20-25$ & 25 & $11 \%$ \\
\hline & & & $>25$ & 189 & $83 \%$ \\
\hline & Negative & 452 & & & \\
\hline \multicolumn{6}{|l|}{$\begin{array}{l}\text { Indeterminate: } \\
68 \\
\end{array}$} \\
\hline \multirow{4}{*}{ N gene: 45} & \multirow{3}{*}{ Positive } & \multirow{3}{*}{51} & $<20$ & 0 & $0 \%$ \\
\hline & & & $20-25$ & 0 & $0 \%$ \\
\hline & & & $>25$ & 51 & $100 \%$ \\
\hline & Negative & 174 & & & \\
\hline \multirow{4}{*}{$\begin{array}{c}\mathrm{N} \text { and } \mathrm{E} \text { genes: } \\
14\end{array}$} & \multirow{3}{*}{ Positive } & \multirow{3}{*}{16} & $<20$ & 0 & $0 \%$ \\
\hline & & & $20-25$ & 0 & $0 \%$ \\
\hline & & & $>25$ & 16 & $100 \%$ \\
\hline & Negative & 54 & & & \\
\hline \multirow{4}{*}{$\begin{array}{c}\text { Late } \\
\text { Amplification: } 9\end{array}$} & \multirow{3}{*}{ Positive } & \multirow{3}{*}{7} & $<20$ & 0 & $0 \%$ \\
\hline & & & $20-25$ & 0 & $0 \%$ \\
\hline & & & $>25$ & 7 & $100 \%$ \\
\hline & Negative & 38 & & & \\
\hline
\end{tabular}




\begin{tabular}{|c|c|c|c|}
\hline Community Tested & Positive Tested & Samples Tested & Positivity Rate \\
\hline \multicolumn{4}{|c|}{ Barangays } \\
\hline Barangay 1 & 16 & 123 & $13 \%$ \\
\hline Barangay 2 & 9 & 90 & $10 \%$ \\
\hline Barangay 3 & 20 & 54 & $37 \%$ \\
\hline Barangay 4 & 0 & 11 & $0 \%$ \\
\hline Barangay 5 & 15 & 46 & $48 \%$ \\
\hline Barangay 6 & 4 & 6 & $67 \%$ \\
\hline \multicolumn{4}{|c|}{ Agencies } \\
\hline Agency 1 & 210 & 1334 & $16 \%$ \\
\hline Agency 2 & 6 & 25 & $24 \%$ \\
\hline Agency 3 & 5 & 17 & $29 \%$ \\
\hline Agency 4 & 4 & 32 & $13 \%$ \\
\hline Agency 5 & 0 & 2 & $0 \%$ \\
\hline Agency 6 & 6 & 52 & $12 \%$ \\
\hline
\end{tabular}

\begin{tabular}{|c|c|c|}
\hline \multicolumn{3}{|c|}{ Number of Test Kits } \\
\hline With Pooling & & Conventional Testing \\
\hline Pools of 5 & 370 & \\
\hline Individual Testing & 1019 & 1828 \\
\hline Total Runs & 1389 & \\
\hline Total Saved Tests & 439 & \\
\hline Percentage of Saved Tests & $24 \%$ & \\
\hline
\end{tabular}

Included in this study are $1596(87 \%)$ males and 232 (13\%) females with an average age of 34 years old taken from different barangays and agencies. Table 3 shows the samples tested and positivity rates for the respective barangays and agencies. In contrast to the $16.5 \%$ positivity rate in the population, Barangays $3,5,6$ had a positivity rate at $37 \%, 48 \%$, and $67 \%$, respectively, while Agencies 3 and 2 had a positivity rate of $29 \%$ and $24 \%$, respectively. Also included in the population are the market vendors and tricycle drivers which had positivity rates of $16.19 \%$ and $15.74 \%$ respectively.

Table 4 shows the number of test kits used with pooled testing in contrast to conventional testing. In comparison to the 1828 test kits that would have been used had conventional testing been done, pooled testing saved $24 \%$ of test kits since only 1389 test kits were used. More so, the overall turnaround time was shortened by 23 hours.

\section{DISCUSSION}

Evaluated are 1828 samples from asymptomatic individuals in a LGU taken on September 2, 2020 to September 8, 2020. The individual samples were grouped into 370 pools (165 negative, 137 positive, and 68 indeterminate pools). Among the 679 individuals that constitute the positive pools, 227 turned out to be positive by individual testing giving a $33 \%$ positivity rate. Among the 340 individuals that constitute the indeterminate pools, 74 turned out to be positive by individual testing giving a $21.7 \%$ positivity rate. Individual testing of the indeterminate pools is necessary since the dilution of samples showed loss of sensitivity in the pooled samples; hence testing of indeterminate pools may reduce the loss of sensitivity in pooling and allows the detection of samples with low viral load. ${ }^{3,5,11}$ Also noted are small number of positive pools $(1.5 \%)$ that did not yield any positive sample when retested individually, this may be attributed to sample carry over, technical and procedural errors.

Review of the individual specimens' ORF Ct-values showed that $6 \%, 11 \%$ and $83 \%$ of the positive pools had an ORF Ct-values of $<20,20-25$ and $>25$, respectively, while all the positive individuals in the indeterminate pools had an ORF Ct-values of $>25$. Further analysis of the samples showed that the positive individuals in the positive pools had an average ORF Ct-value of 30.23. On the other hand, the pools with $\mathrm{N}$ gene only, $\mathrm{N}$ and $\mathrm{E}$ genes, and late amplification had an average ORF Ctvalues of $34.93,34.95$ and 36.52 , respectively. These data showed that despite the dilution effect of pooling, PCMC's testing laboratory was still able to obtain congruence in the Ct-values of the pooled and individual samples. Although an indirect measure of viral load, the assessment of Ct-values is necessary since it can be a relative measure of viral copies if the samples are tested in a standard condition. ${ }^{3,19}$ This was supported in a multicenter study done in Bahrain, wherein it was said that symptomatic presentation was significantly associated with lower Ctvalues. ${ }^{20}$ Furthermore, a study done by Faíco-Filho et al., showed that individuals with severe COVID-19 had a median Ct-value of 21.5, while mild and moderate illnesses had Ct-values of 22 and 27, respectively. ${ }^{21}$

In major universities in the United States, pooled surveillance testing to detect person with asymptomatic infection was used. The residents in these universities were tested twice weekly, off-campus undergraduates were tested once or twice a week and graduate students were tested every week. Using pooling, they were able to test 10,265 students from which 84 samples were positive and $51 \%$ of the positive students were asymptomatic. All the positive students were quarantined, and testing frequency were increased in areas with infection. Due to the test compliance achieved in this study, pooled surveillance testing was made available to the faculty, staff and student athletes. $^{22}$ Observed in this study are barangays and agencies with higher positivity rates than the population's positivity of $16.5 \%$. Unfortunately, the sample groups in this study were not proportionally grouped and were limited by the retrospective nature of the study, hence the difficulty to survey infection in the population. In a position paper by the PSP, the utility of pooled testing to contain viral transmission in the community was acknowledged. They proposed that communities exposed to a confirmed SARS-CoV-2 positive individual must be assessed for development of symptoms, 5 days after exposure from the index case. All exposed symptomatic members of the community must be tested individually, while all the asymptomatic members of the community shall be subjected to pooled RT-PCR. ${ }^{23}$

In comparison to conventional testing, the use of pooling strategies conserved around $24 \%$ of tests kits, a saving of php 1,570,303. Despite the substantial savings in pooled testing, the laboratory must be cautious since test savings will decline as the positivity/prevalence rates increase. To avoid this, the testing laboratory may pool the family members, work sectors, and communities together. ${ }^{3}$ In general, pooled testing shortens the laboratory's turnaround time, 
however part of the limitation of pooling is the increase in the turnaround time of positive individuals. In this population, the turnaround time of all the samples is 73 hours, while the projected turnaround time of individual RT-PCR tests of 1828 samples is 96 hours if pooled testing was not done. Also, with the use of pooled testing, less personnel and resources were used in the laboratory.

\section{CONCLUSION}

Pooled testing is a good strategy to catch SARS-CoV-2 infection in asymptomatic individuals. It is cost-effective, efficient and may be used to mass test the general population, LGUs and provinces where resources are sparse. Pooled testing done in the population showed high pick-up rate in those with low ORF Ct-value an indirect measure of the relative amount of viral load.

\section{RECOMMENDATION}

Pooled testing is cost-effective and beneficial in the screening of asymptomatic population. It may serve as a useful tool to assess the SARS-CoV-2 infectivity in the community. When conducting pooled testing, the pool size must be adjusted in concordance with the population's prevalence. It is recommended to conduct a study in both symptomatic and asymptomatic individuals with comparison of Ct-values and disease severity. Despite the congruence of ORF Ct-values in pooled and individual tests, an in-depth study with emphasis on the indeterminate pools is recommended. A study which uses pooled testing that are limited to high-risk population like tricycle drivers and market vendors may be done. A prospective study that focuses on disease surveillance and population demographics is warranted.

\section{LIMITATION}

Due to the retrospective nature of the study, the data in the community and workplace sectors are not proportional, hence it is difficult to calculate the incidence of infection for the sectors. Since this is a descriptive study, testing of the negative pools was not performed, in line with this, there is a minute risk of not catching the weak positive individuals due to sample dilution. Although there is an overall decrease in the turnaround time, samples of the positive individual will have to be tested twice, increasing its turnaround time. Additional training and technical skills are needed by the medical technologists and pathologists to perform pooled testing.

\section{ACKNOWLEDGMENT}

The authors would like to acknowledge all the swabbers, receptionists, encoders and analysts at the PCMC's COVID laboratory for all their hard work.

\section{STATEMENT OF AUTHORSHIP}

All authors fulfilled the ICMJE authorship criteria.

\section{AUTHOR DISCLOSURE}

The authors declared no conflict of interest.

\section{FUNDING SOURCE}

None.

\section{REFERENCES}

1. Valencia DN. Brief Review on COVID-19: the 2020 pandemic caused by SARS-CoV-2. Cureus. 2020;12(3):e7386. PMID: 32337113. PMCID: PMC7179986. https://doi.org/10.7759/cureus.7386.

2. Department Memorandum No. 2020-0258. Updated Interim Guidelines on Expanded Testing for COVID-19. Department of Health, Republic of the Philippines. https://doh.gov.ph/node/24149.

3. Lo R, Barrientos A, Espiritu B, Santiago FK, Tandoc A, Velasco J, Yanez S. An Evaluation of pooling strategies for RT-qPCR testing for SARS-CoV-2 infection: a pragmatic multi- site parallel operational study. Philipp J Pathol. 2020;5(2):12-33. https://doi. org/10.21141/pjp.2020.12.

4. Department Memorandum No. 2020-0539. Interim Guidelines on the Conduct of COVID-19 Pooled Testing. Department of Health, Republic of the Philippines. https://doh.gov.ph/sites/default/files/ health-update/dm2020-0539.pdf.

5. Interim Guidance for Use of Pooling Procedures in SARS-CoV-2 Diagnostic, Screening, and Surveillance Testing. (n.d.). Retrieved September 15, 2020, from https://www.cdc.gov/coronavirus/2019-ncov/lab/ pooling-procedures.html.

6. Coronavirus disease 2019 (COVID-19) - WHO. (n.d.). Retrieved September 13, 2020, from https:// www.who.int/docs/default-source/coronaviruse/ situation-reports/20200323-sitrep-63-covid-19. pdf?sfvrsn=b617302d_4.

7. Guo Y, Cao Q, Hong $\bar{Z}$, et al. The origin, transmission and clinical therapies on coronavirus disease 2019 (COVID-19) outbreak - an update on the status. Mil Med Res. 2020;7(1):11. PMID: 32169119. PMCID: PMC7068984. https://doi.org/10.1186/s40779-02000240-0.

8. Wiersinga WJ, Rhodes A, Cheng AC, Peacock SJ, Prescott HC. Pathophysiology, transmission, diagnosis, and treatment of coronavirus disease 2019 (COVID-19). JAMA. 2020;324(8):782-93. PMID: 32648899. https://doi.org/10.1001/jama.2020.12839.

9. Gao, Z, Xu Y, Sun C, et al. A systematic review of asymptomatic infections with COVID-19. J Microbiol Immunol Infect. 2021;54(1):12-6. PMID: 32425996. PMCID: PMC7227597. https://doi.org/10.1016/j.jmii. 2020.05.001.

10. Rao SN, Manissero D, Steele V, Pareja J. Correction to: A systematic clinical review of the utility of cycle threshold values in the context of COVID-19. Infect Dis Ther. 2020;9(3):587. PMID: 32809140. PMCID: PMC7431897. https://doi.org/10.1007/s40121-02000328-z.

11. Interim Guidance for Use of Pooling Procedures in SARS-CoV-2 Diagnostic, Screening, and Surveillance Testing (n.d.). Retrieved September 15, 2020, from https://www.cdc.gov/coronavirus/2019-ncov/lab/ pooling-procedures.html. 
12. WHO Coronavirus Disease (COVID-19) Dashboard. (n.d.). Retrieved September 13, 2020, from https:// covid19.who.int/.

13. Philippines: WHO Coronavirus Disease (COVID-19) Dashboard. (n.d.). Retrieved September 13, 2020, from https://covid19.who.int/region/wpro/country/ph.

14. Ben-Ami R, Klochendler A, Seidel M, et al. Largescale implementation of pooled RNA-extraction and RT-PCR for SARS-CoV-2 detection. Clin Microbiol Infect. 2020;26(9):1248-53. PMID: 32585353. PMCID: PMC7308776. https://doi.org/10.1016/j.cmi. 2020.06.009.

15. Das S, Lau AF, Youn J, Khil PP, Zelazny AM, Frank KM. Pooled testing for surveillance of SARS-CoV-2 in asymptomatic individuals. J ClinVirol. PMID: 32920431. PMCID: PMC7470739. https://doi.org/ 10.1016/j.jcv.2020.104619.

16. Lohse S, Pfuhl T, Berkó-Göttel B, et al. Pooling of samples for testing for SARS-CoV-2 in asymptomatic people. Lancet Infect Dis. 2020;20(11):1231-2. PMID: 32530425. PMCID: PMC7194818. https://doi. org/10.1016/S1473-3099(20)30362-5.

17. Agoti CN, Mutunga M, Lambisia AW, et al. Pooled testing conserves SARS-CoV-2 laboratory resources and improves test turn-around time: experience on the Kenyan Coast. Wellcome Open Res. 2021;5:186. PMID: 33134555. PMCID: PMC7590893. https://doi. org/10.12688/wellcomeopenres.16113.2.

18. Mastrianni, D., Falivena, R., Brooks, T., Mcdermott, B., Tan, J., Vandell, R., \& Holland, M. (2020). Pooled Testing for SARS-CoV-2 in Hospitalized Patients. Journal of Hospital Medicine, 15(9), 538- 539. doi:10.12788/jhm.3501.
19. An overview of cycle threshold values and their role in SARS-CoV-2 real-time PCR test interpretation. Retrieved January 30, 2021. https://www.publichealth ontario.ca/-/media/documents/ncov/main/2020/09/ cycle-threshold-values-sars-cov2-pcr.pdf?la=en.

20. Abdulrahman A, Mallah S, AlAwadhi AI. Association between RT-PCR Ct values and COVID-19 new daily cases: a multicenter cross- sectional study. https://doi. org/10.1101/2020.12.07.20245233.

21. Faíco-Filho KS, Passarelli VC, Bellei N. Is higher viral load in SARS-CoV-2 associated with death? American J Trop Med Hyg. 2020;103(5):2019-21. PMID: 32996443. PMCID: PMC7646800. https://doi. org/10.4269/ajtmh.20-0954.

22. Denny TN, Andrews L, Bonsignori M, et al. Implementation of a pooled surveillance testing program for asymptomatic SARS-CoV-2 infections on a college campus - Duke University, Durham, North Carolina, August 2-October 11, 2020. MMWR Morb Mortal Wkly Rep. 2020;69(46):1743-7. PMID: 33211678. PMCID: PMC7676642. https://doi.org/ 10.15585/mmwr.mm6946e1.

23. Padua Jr R. The Philippine Society of Pathologists, Inc. Statement on the current pandemic situation strategic testing to assist in managing local COVID-19 outbreaks. 2021.

Disclaimer: This journal is OPEN ACCESS, providing immediate access to its content on the principle that making research freely available to the public supports a greater global exchange of knowledge. As a requirement for submission to the PJP, all authors have accomplished an AUTHOR FORM, which declares that the ICMJE criteria for authorship have been met by each author listed, that the article represents original material, has not been published, accepted for publication in other journals, or concurrently submitted to other journals, and that all funding and conflicts of interest have been declared. Consent forms have been secured for the publication of information about patients or cases; otherwise, authors have declared that all means have been exhausted for securing consent.

\section{Publish in the new PJP.} Visit our website: htp://philippinejournalofpathology.org 


\section{APPENDICES}

\section{Appendix 1. Data Collection Form}

\begin{tabular}{|c|c|c|c|c|c|c|c|}
\hline Pooled Sample & Genes & Ct-value & Result & Individual Samples & Genes & Ct-value & Result \\
\hline \multirow[t]{20}{*}{ Pooled Sample No. 1} & Control & & & \multirow[t]{4}{*}{ Individual Sample 1} & Control & & \\
\hline & ORF1a/b & & & & ORF1a/b & & \\
\hline & $\mathrm{E}$ & & & & $\mathrm{E}$ & & \\
\hline & $\mathrm{N}$ & & & & $\mathrm{N}$ & & \\
\hline & & & & \multirow[t]{4}{*}{ Individual Sample 2} & Control & & \\
\hline & & & & & ORF1a/b & & \\
\hline & & & & & $\mathrm{E}$ & & \\
\hline & & & & & $\mathrm{N}$ & & \\
\hline & & & & \multirow[t]{4}{*}{ Individual Sample 3} & Control & & \\
\hline & & & & & ORF1a/b & & \\
\hline & & & & & $\mathrm{E}$ & & \\
\hline & & & & & $\mathrm{N}$ & & \\
\hline & & & & \multirow[t]{4}{*}{ Individual Sample 4} & Control & & \\
\hline & & & & & ORF1a/b & & \\
\hline & & & & & $\mathrm{E}$ & & \\
\hline & & & & & $\mathrm{N}$ & & \\
\hline & & & & \multirow[t]{4}{*}{ Individual Sample 5} & Control & & \\
\hline & & & & & ORF1a/b & & \\
\hline & & & & & $\mathrm{E}$ & & \\
\hline & & & & & $\mathrm{N}$ & & \\
\hline
\end{tabular}

\section{Appendix 2. Dummy Tables}

Table 1. Pooled samples interpretation

\begin{tabular}{|c|l|l|}
\hline Pooled Samples Interpretation & Number & Percentage \\
\hline Negative & & \\
\hline Positive & & \\
\hline Indeterminate & & \\
\hline Total Number of Pools & & \\
\hline
\end{tabular}

Table 2. Individual samples interpretation

\begin{tabular}{|c|c|c|c|c|c|}
\hline $\begin{array}{l}\text { Pooled } \\
\text { Samples }\end{array}$ & $\begin{array}{l}\text { Individual } \\
\text { Samples } \\
\text { Interpretation }\end{array}$ & Number & $\begin{array}{l}\text { ORF1a/b } \\
\text { (Ct-values) }\end{array}$ & Number & $\begin{array}{l}\text { Ct-values } \\
\text { positive \% }\end{array}$ \\
\hline \multicolumn{6}{|l|}{ Negative: } \\
\hline \multicolumn{6}{|l|}{ Positive: } \\
\hline & \multirow{3}{*}{ Positive } & & $<20$ & & \\
\hline & & & $20-25$ & & \\
\hline & & & $>25$ & & \\
\hline & Negative & & & & \\
\hline \multicolumn{6}{|l|}{ Indeterminate: } \\
\hline \multirow{4}{*}{ N gene: } & \multirow{3}{*}{ Positive } & & $<20$ & & \\
\hline & & & $20-25$ & & \\
\hline & & & $>25$ & & \\
\hline & Negative & & & & \\
\hline \multirow{4}{*}{$\mathrm{N}$ and $\mathrm{E}$ genes: } & \multirow{3}{*}{ Positive } & & $<20$ & & \\
\hline & & & $20-25$ & & \\
\hline & & & $>25$ & & \\
\hline & Negative & & & & \\
\hline \multirow{4}{*}{$\begin{array}{c}\text { Late } \\
\text { Amplification: }\end{array}$} & \multirow{3}{*}{ Positive } & & $<20$ & & \\
\hline & & & $20-25$ & & \\
\hline & & & $>25$ & & \\
\hline & Negative & & & & \\
\hline
\end{tabular}

Table 3. Individual sample results summary

\begin{tabular}{|c|c|c|c|c|}
\hline Pooled Samples & $\begin{array}{c}\text { Negative } \\
\text { Result }\end{array}$ & $\begin{array}{c}\text { Positive } \\
\text { Result }\end{array}$ & $\begin{array}{c}\text { Total } \\
\text { Samples }\end{array}$ & $\begin{array}{c}\text { Positivity } \\
\text { Rate }\end{array}$ \\
\hline Negative Pools & & & & \\
\hline Positive Pools & & & & \\
\hline Indeterminate Pools & & & & \\
\hline Total & & & & \\
\hline
\end{tabular}

Table 4. Test kits used in pooled testing vs conventional testing

\begin{tabular}{|c|c|}
\hline \multicolumn{2}{|c|}{ Number of Test Kits } \\
\cline { 1 - 2 } With Pooling & \multirow{2}{*}{ Conventional Testing } \\
\hline Pools of 5 & \\
\hline Individual Testing & \\
\hline Total Runs & \\
\hline Total Saved Tests & \\
\hline Percentage of Saved Tests & \\
\hline \multicolumn{2}{|c|}{} \\
\hline
\end{tabular}

